\title{
A North-South model with technological spillovers, environmental degradation and structural change
}

Anton Bondarev

Alfred Greiner 


\title{
A North-South model with technological spillovers, environmental degradation and structural change
}

\author{
Anton Bondarev* $\quad$ Alfred Greiner ${ }^{\dagger}$
}

July 8, 2014

\begin{abstract}
In this paper we present and analyze a stylized model of endogenous growth with international technology spillover effects from the North to the South. The model allows for endogenous structural change and environmental degradation that reduces world output. We find that within this framework the costless technological spillovers foster structural change in both more and less advanced economies. Moreover, we can show that under technological spillovers the degradation of the environment is expected to be lower even without government interventions and we highlight the role of endogenous structural change in generating this outcome.
\end{abstract}

JEL classification: Q55, Q58, O31, O34, O41

Keywords: Technological Spillovers, Endogenous Growth, Environmental Impact, Endogenous Structural Change, Creative Destruction

*Department of Economics, University of Basel, Peter Merian-Weg, 6, 4002 Basel, Switzerland, e-mail: anton.bondarev@unibas.ch

${ }^{\dagger}$ Department of Business Administration and Economics, Bielefeld University, Universitätstraße 25, 33615 Bielefeld, Germany, e-mail: agreiner@wiwi.uni-bielefeld.de

Financial support from the Bundesministerium für Bildung und Forschung (BMBF) is gratefully acknowledged (grant 01LA1105C). This research is part of the project 'Climate Policy and the Growth Pattern of Nations (CliPoN)'. 


\section{Introduction}

In this paper we present a stylized North-South endogenous growth model that allows for structural change and environmental degradation, where the South benefits form R\&D investment in the North through spillover effects of knowledge. Structural change occurs as an endogenous phenomenon resulting from the introduction of new technologies that are developed with the help of $R \& D$ investment, with new technologies replacing old ones. Simultaneously, the existing technologies are continuously improved through vertical innovations. Both the North and the South invest in horizontal and vertical innovations but the North represents the more developed economy that disposes of a higher stock of physical capital and of a higher level of knowledge. Since we consider a world economy in which both economies invest in new technolgies and their improvement, our framework describes the situation between industrialized countries and emerging market economies, or the case of two industrialized economies with one lagging behind, rather than the one between industrialized economies and developing economies. In addition, production goes along with environmental degradation that negatively affects output in both economies. The starting point of our analysis are the two papers by Bondarev and Greiner (2014a) and Bondarev and Greiner (2014b) where the basic model with and without environmental degradation is presented, however, without considering a North-South interaction but restricting itself to the autarky case only.

The goal of this paper here is twofold: First, we intend to work out the effects that arise when the autarky model is extended to an open economy version with spillovers of knowledge from the North to the South. In particular, we are interested in the effects with respect to the structural change in the two economies under consideration. Second, we are interested in the comparative effects of environmental degradation in the model under autarky compared to those in the two country world. Again, special emphasis is put on the role played by the endogenous structural change what has not been done in the economics literature as far as we know.

An early paper in the economics literature that deals with technology spillovers 
in an endogenous growth framework is the contribution by Rivera-Batiz and Romer (1991). These authors assume that the spillovers go in both directions such that the increase in productivity in each country positively depends on the level of technology in the other country. The analysis of this paper shows that allowing for spillover effects implies a higher growth rate compared to the autarky case since the productivity grows at a higher rate leading to a larger spectrum of intermediate goods. The effects of technology diffusion and trade within endogenous growth models allowing for heterogeneous firms has been analyzed by Baldwin and Robert-Nicoud (2008) and Unel (2010). These authors find that the exposure to trade has an ambiguous effect on economic growth although it raises the average productivity. The answer to the question of whether economic growth rises or declines depends on the exact nature of the innovation technology and its connection to international trade.

As concerns the effects of environmental pollution in a multi-country work, a seminal paper is the contribution by Chichilinsky (1994). There, the focus is put on property rights and it is shown that the latter create a motive for trade among otherwise identical regions. Two identical regions will trade if the South has badly defined property rights on environmental resources. Trade with a region with well defined property rights, the North, leads to an overconsumption of resource intensive goods imported from the South. Imposing a tax on the use of resources in the South can lead to even more overextraction and a property rights policies may be more effective. The latter contribution resorts to a static framework to derive its results but does not take into account dynamic aspects. Dynamic North-South models that study the interrelation betwen economic activities and the environment often resort to dynamic game theory. For example, Alemdar and Özyildrim (1998) and Alemdar and Özyildrim (2002) present North-South models, where the North imports raw materials from the South at a monopoly price to produce manufactured goods that are consumed in both regions. There exists a technology diffusion process from the North to the South and the extraction of resources causes environmental degradation. The second contribution, in contrast to the first, assumes that waste material is dumped in the South and it allows for multiple resource owners in the South and damages from resource extraction are 
only local. The analysis demonstrates that an uncoordinated resource extraction can cause a significant reduction of welfare in the South and cooperation between resource producers in the South raises global welfare, with the South gaining to a larger degree. Further, even without cooperation, both regions are better off when productive activities are less polluting and when knowledge spillovers are larger.

As mentioned above, with this paper we intend to contribute to the literature that analyzes the effects of international technology spillovers as concerns economic growth and environmental degradation, where we pay special attention to structural change. The rest of the paper is organized as follows. The next section briefly presents the structure of the North-South growth model. Section 3 gives the solution of the model and section 4 derives the impacts of technology spillovers and of environmental pollution. Section 5, finally, discusses the model presented here and concludes.

\section{The basic model}

The baseline model represents two decentralised economies which interact with each other only through $R \& D$ channels and do not compete on product markets. First, we present the model neglecting environmental degradation. Later on this assumption is relaxed to account for the influence of the environment on the overall dynamics.

There are two countries, marked N and S for North and South, respectively. Every country $\mathrm{k} \in\{\mathrm{N}, \mathrm{S}\}$ is described by the framework with endogenous structural change as in Bondarev and Greiner (2014a) with both vertical and horizontal R\&D. We assume symmetric economies with respect to the labour force that is constant over time. In every economy labour equals total population and is distributed across the existing range of sectors at every point in time $t$ :

$$
\begin{aligned}
& \forall \mathrm{k} \in\{\mathrm{N}, \mathrm{S}\}: \\
& L^{\mathrm{k}}=\int_{N_{\min }(t)}^{N_{\max }(t)} L^{\mathrm{k}}(i, t) d i \\
& N_{\min }(t)<N_{\max }(t)<N(t)
\end{aligned}
$$


Here $L^{\mathrm{k}}$ is the total labour in each of the economies, $L(i, t)$ is the employment in sector $i$ at time $t$ (changing in time), $N(t)$ is the number of technologies (range) being invented up to time $t, N_{\max }(t)$ is the range of manufacturing sectors with positive operating profit and $N_{\min }(t)$ is the range of technologies which are no longer profitable and are not used in production. Note that both limits in the integral above are dynamic denoting ongoing structural change in the economy.

The range of invented technologies $N(t)$ is common for both countries and represents the state of fundamental knowledge in the world. Provided symmetry in exogenous parameters of the model, the ranges of operating sectors are also similar across countries and given by the number $N_{\max }(t)-N_{\min }(t)$ at any point in time.

\subsection{Households}

In each country households are maximizing their utility from consumption of the available range of products (the same as the range of operating sectors). The objective functional of the household is

$$
\forall \mathrm{k} \in\{\mathrm{N}, \mathrm{S}\}: J^{\mathrm{k}, H}=\int_{0}^{\infty} \mathrm{e}^{-\rho t} U\left(C^{\mathrm{k}}\right) d t
$$

with $U(C)=\ln C$ being the utility function.

The representative household in each country is maximizing utility from consumption $C^{k}$ over a continuum of differentiated products from existing sectors

$$
C^{\mathrm{k}}=\left[\int_{N_{\min }}^{N_{\max }}\left(C_{i}^{\mathrm{k}}\right)^{\frac{\varepsilon-1}{\varepsilon}} d i\right]^{\frac{\varepsilon}{\varepsilon-1}}
$$

where $\varepsilon$ is the elasticity of substitution between goods.

The flow budget constraint of the household is for both countries

$$
\dot{K}^{\mathrm{k}}(t)=r K^{\mathrm{k}}(t)+w L^{\mathrm{k}}-E^{\mathrm{k}}(t),
$$

where $K^{\mathrm{k}}(t)$ is country-specific capital, $E^{\mathrm{k}}(t)$ denotes expenditures and $r$ is the interest 
rate, being assumed equal across countries. Since the total labor is constant and similar in size in each of the economies, the wage rate $w$ is taken as a numeraire and normalized to one further on.

Demand for each product follows standard derivations as in the benchmark model:

$$
C_{i}^{\mathrm{k}}(t)=E^{\mathrm{k}}(t) \frac{\left(P_{i}^{\mathrm{k}}(t)\right)^{-\varepsilon}}{\int_{N_{\min }}^{N_{\max }}\left(P_{j}^{\mathrm{k}}(t)\right)^{1-\varepsilon} d j},
$$

where $P_{i}^{\mathrm{k}}$ denotes the price of good $i$.

The standard Euler equation implies that the optimal growth rate for expenditure is given by

$$
\frac{\dot{E}^{\mathrm{k}}}{E^{\mathrm{k}}}=r-\rho
$$

\subsection{The manufacturing sector}

For both countries manufacturing sectors are isolated and do not compete with foreign producers. The dynamics is fully analogous to Bondarev and Greiner (2014a) in this respect.

Goods producers employ labor and buy technology from the R\&D sector. With these inputs they produce the goods which they sell to the consumer. Output of good $i$ is given by:

$$
Y_{i}^{\mathrm{k}}(t)=\left(A_{i}^{\mathrm{k}}(t)\right)^{\alpha} L_{i}^{\mathrm{k}}(t)
$$

with $A_{i}^{\mathrm{k}}$ giving the productivity. The profit of firm $i$ is

$$
\Pi_{i}^{\mathrm{k}}(t)=P_{i}^{\mathrm{k}}(t) Y_{i}^{\mathrm{k}}(t)-L_{i}^{\mathrm{k}}(t)-\Psi
$$

where $\Psi$ is a fixed operating cost assumed to be equal for both countries.

The only use for output is consumption, so that $C_{i}=Y_{i}$. Firm $i$, therefore, sets its price to

$$
P_{i}^{\mathrm{k}}(t)=\frac{\varepsilon}{\varepsilon-1}\left(A_{i}^{\mathrm{k}}(t)\right)^{-\alpha} .
$$

Inserting (5) and (9) into (7) yields (piecewise defined) labour demand (for each coun- 
try)

$$
L^{\mathrm{k}}(i)=\left\{\begin{array}{l}
0, t<\tau_{\max }(i), \tau_{\max }(i): \Pi_{i}^{\mathrm{k}}=0, \dot{\Pi_{i}^{\mathrm{k}}}>0 ; \\
\frac{\epsilon-1}{\epsilon} E^{\mathrm{k}} \frac{\left(A_{i}^{\mathrm{k}}\right)^{-\alpha(1-\epsilon)}}{\int_{\max }^{N_{\min }}\left(A_{j}^{\mathrm{k}}\right)^{-\alpha(1-\epsilon)} d j}, \tau_{\max }(i)<t \leq \tau_{\min }(i), \tau_{\min }(i): \Pi_{i}^{\mathrm{k}}=0, \dot{\Pi}_{i}^{\mathrm{k}}<0 ; \\
0, t>\tau_{\min }(i) .
\end{array}\right.
$$

Here and further throughout the paper denote

- $\tau_{\min }=N_{\min }^{-1}(i)$, time when product (technology) $i$ becomes outdated and the profit of the manufacturing sector decreases below zero;

- $\tau_{\max }=N_{\max }^{-1}(i)$, time when product (technology) $i$ becomes profitable and the manufacturing sector starts producing positive amounts of the consumption good;

- $\tau_{0}=N^{-1}(i)$, time when technology $i$ is invented through horizontal innovations.

Technology is acquired by the manufacturing sector in the form of a patent of finite duration. Pricing for this patent therefore follows Nordhaus (1967), Romer (1990) and Grimaud and Rouge (2004): the price for the patent equals the total value of profits which can be derived from it. Since positive profits may be extracted by the manufacturing firm only during a limited period of time, the price of the patent is also defined over a limited duration. After the patent expires because the technology does not yield positive profits any longer, the technology is freely available for production to everyone. However, due to the process of out-dating of technologies, older technologies are not used in production despite their zero price. The price of the patent is,

$$
\begin{aligned}
& p_{A}^{\mathrm{k}}(i) \stackrel{\text { def }}{=} \int_{\tau_{\max }}^{\tau_{\min }} \mathrm{e}^{-r\left(t-\tau_{0}\right)} \Pi_{i}^{\mathrm{k}} d t= \\
& \left.\int_{\tau_{\max }}^{\tau_{\min }} \mathrm{e}^{-r\left(t-\tau_{0}(i)\right)}\left(\frac{1}{\epsilon} E^{\mathrm{k}} \frac{\left(A_{i}^{\mathrm{k}}\right)^{-\alpha(1-\epsilon)}}{\int_{N_{\min }}^{N_{\max }}\left(A_{j}^{\mathrm{k}}\right)^{-\alpha(1-\epsilon)} d j}\right) \Psi\right) d t .
\end{aligned}
$$

The point in time at which patent $i$ starts, $\tau_{\max }$, is endogenously determined through 
the process of horizontal innovations while the effective time of the expiration of the patent, $\tau_{\min }$, is endogenously determined from the demand for the manufactured patented product $i$.

\subsection{The R\&D sector}

For each country the process of vertical innovations is described by the same laws as in the stand-alone model except for the possibility of technological spillover. We limit ourselves to the case where one of the countries benefits from the technology spillover (constant leadership case). For the advanced country (North) the process of development of new products is fully similar to the baseline model:

$$
\begin{gathered}
V^{\mathbb{N}}=\max _{g} \int_{0}^{\infty} e^{-r t} \int_{N_{\min }(t)}^{N(t)} p_{A}^{\mathrm{N}}(i)-\frac{1}{2}\left(g^{\mathrm{N}}(i, t)\right)^{2} d t ; \\
\text { s.t. } \\
\forall i \in\left[N_{\min }, N\right]: \dot{A}^{\mathrm{N}}(i, t)=\gamma^{\mathrm{N}} g^{\mathrm{N}}(i, t)-\beta A^{\mathrm{N}}(i, t) \\
\int_{N_{\min (t)}(t)}^{N(t)} g^{\mathrm{N}}(i, t) d i=K^{\mathrm{N}}(t)-u^{\mathrm{N}}(t) .
\end{gathered}
$$

At the same time the less developed country benefits from the technological spillover proportional to the technology gap between itself and the developed economy:

$$
\begin{gathered}
V^{\mathrm{S}}=\max _{g} \int_{0}^{\infty} e^{-r t} \int_{N_{\min }(t)}^{N(t)} p_{A}^{\mathrm{S}}(i)-\frac{1}{2}\left(g^{\mathrm{S}}(i, t)\right)^{2} d i d t ; \\
\forall i \in\left[N_{\min }, N\right]: \dot{A}^{\mathrm{S}}(i, t)=\gamma^{\mathrm{S}} g^{\mathrm{S}}(i, t)-\beta A^{\mathrm{S}}(t)+\theta\left(A^{\mathrm{N}}(t)-A^{\mathrm{S}}(t)\right) \\
\int_{N_{\min }(t)}^{N(t)} g^{\mathrm{S}}(i, t) d i=K^{\mathrm{S}}(t)-u^{\mathrm{S}}(t) .
\end{gathered}
$$

where: 
- $g^{\mathrm{k}}(i, t)$ are investments into the increase of productivity of technology $i$ at time $t$ by country $\mathrm{k}$;

- $A^{\mathrm{k}}(i, t)$ is the state of productivity of technology $i$ at time $t$ in country $\mathrm{k}$;

- $\gamma^{\mathrm{k}}$ is the efficiency of investments into productivity in country $\mathrm{k}$;

- $\theta$ is the speed of technological spillover from the North to the South;

- $\beta$ is the decay rate of technology in the absence of investments;

- $K^{\mathrm{k}}(t)-u^{\mathrm{k}}(t)$ are resources available for vertical innovations given by the accumulated capital minus horizontal innovations investments.

As concerns the source for those spillovers, one can think of two sources. First, it is possible that more developed economies foster technical progress in less developed countries as a means of development aid. This may occur in form of a direct knowledge transfer or by training students of the less developed country in the more developed one, for example. In that case, one can speak of a cooperation between these two economies. Second, knowledge can never be completely kept secret so that it may be transferred from one country to another even if the developed country does not actively contribute to its dissemination. This holds all the more when the less developed economy is trying to acquire the knowledge of the developed economy.

The only incentive for horizontal innovations is the potential profit from selling the new technology to manufacturing firms. Since horizontal innovations have zero productivity at the time when they are invented, ${ }^{1}$ the value of horizontal $R \& D$ consists in expected future profits that arise when an innovation becomes profitable as a result of vertical innovations (analogous to Peretto and Connolly (2007)):

$$
V_{N}^{\mathrm{k}}=\max _{u(\cdot)} \int_{0}^{\infty} \mathrm{e}^{-r t}\left(\left.\left(\delta_{\mathrm{N}} u^{\mathrm{N}}(t)+\delta_{\mathrm{S}} u^{\mathrm{S}}(t)\right) \pi_{\mathrm{k}}^{R}(i, t)\right|_{i=N}-\frac{1}{2}\left(u^{\mathrm{N}, \mathrm{S}}(t)\right)^{2}\right) d t
$$

\footnotetext{
${ }^{1}$ In this sense, we differ between the invention of a new technology and its economic use.
} 
where $\left.\pi_{\mathrm{k}}^{R}(i, t)\right|_{i=N}$ denotes the profit from the subsequent development of the new technology $i=N$ for country k. It is defined as:

$$
\pi_{\mathrm{k}}^{R}(i, t)=p_{A}^{\mathrm{k}}(i)-\frac{1}{2} \int_{\tau_{0}(i)}^{\tau_{\min }(i)} \mathrm{e}^{-r\left(t-\tau_{0}(i)\right)}\left(g^{\mathrm{k}}(i, t)\right)^{2} d i
$$

stating that the profit equals the difference between the price of the patent and the accumulated investments into the technology development during the life of the technology. The change in the range of technologies in the world, then, is the result of the $\mathrm{R} \& \mathrm{D}$ investments in these two regions:

$$
\dot{N}=\delta_{\mathbb{N}} u^{\mathrm{N}}(t)+\delta_{\mathrm{S}} u^{\mathrm{S}}(t)
$$

\section{Solution and basic results}

\subsection{Vertical innovations}

We limit ourselves to the open-loop solution, since it is difficult to formulate a HJB pair for the resource-constrained differential game, see e.g. Dockner et al. (2000). With homogeneous efficiency of investments across technologies within the country, the optimal investments for every technology are just proportional to the total available research capital minus variety expansion investments as long as the derivative of the patent price (10) w.r.t. productivity $A_{i}$ does not depend on $i$. That this is indeed the case is formally proved in the benchmark model. It is sufficient to note that the patent price equation is the same for the technological spillover model as in the benchmark case, thus giving the same result:

$$
g^{\mathrm{k}}(i, t)=\frac{K^{\mathrm{k}}-u^{\mathrm{k}}}{N-N_{\min }}
$$


At the same time the evolution of productivity is different for the North and the South:

$$
\begin{aligned}
& \dot{A}^{\mathrm{N}}=\frac{K^{\mathrm{N}}-u^{\mathrm{N}}}{N-N_{\text {min }}}-\beta A^{\mathrm{N}}, \\
& \dot{A}^{\mathrm{S}}=\frac{K^{\mathrm{S}}-u^{\mathrm{S}}}{N-N_{\text {min }}}-\beta A^{\mathrm{S}}+\theta\left(A^{\mathrm{N}}-A^{\mathrm{S}}\right) .
\end{aligned}
$$

as long as $A^{\mathrm{N}}(t)>A^{\mathrm{S}}(t)$.

Since horizontal investments are constant, the dynamics solely depends on the capital evolution. The latter is analogous to the stand-alone baseline model and given by:

$$
K^{\mathrm{k}}(t)=\mathrm{e}^{r t}\left(K_{0}^{\mathrm{k}}-\frac{1}{(\epsilon-1) r} L\right)+\frac{1}{r(\epsilon-1)} L
$$

With similar labor in both countries, the difference in evolution of capital is fully defined by the difference in initial asset holdings of households which is a natural measure of the state of development of the economy. With similar initial asset holdings no technological spillover is possible as further discussions below show.

Denote the capital available for vertical innovations as $G^{\mathrm{N}}, G^{\mathrm{S}}$ for both countries. For leadership to be constant it is sufficient to have $G^{\mathrm{N}}>G^{\mathrm{S}}, \forall t$. Given linear variety investments (because of homogeneous technologies) and monotonic capital accumulation (because of constant expenditures $E$ ) it amounts to the condition on initial capital endowments in both countries. With $K_{0}^{\mathrm{N}}>K_{0}^{\mathrm{S}}$ the follower will never catch-up with the leader in productivity, but the South productivity will be still higher than in the autarky case as the illustration in Figure 1 shows. This gives rise to the following Proposition.

\section{Proposition 1 (Evolution of productivities)}

For constant technological spillovers from the North to the South, it is sufficient to have $K_{0}^{N}>K_{0}^{S}$ in the symmetric case. In this case, productivity in the South $A^{\mathrm{S}}(i, t)$ grows faster for each sector than in the absence of spillovers while the North productivity $A^{\mathrm{N}}(i, t)$ is unaffected by it.

Proof: As long as $K_{0}^{\mathrm{N}}>K_{0}^{\mathrm{S}}$ we have $\forall t, K^{\mathrm{N}}>K^{\mathrm{S}}$. As long as horizontal innovations 


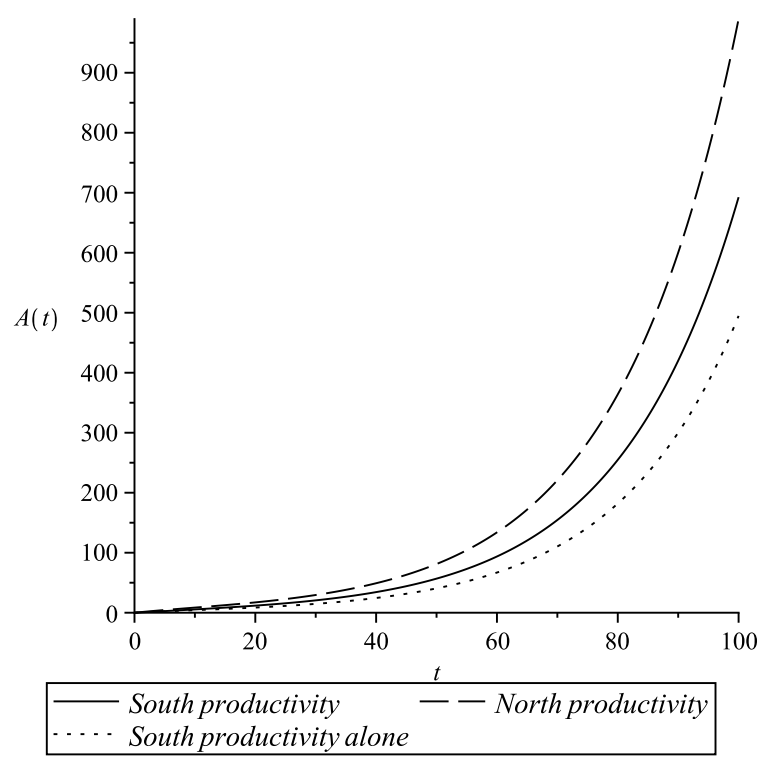

Figure 1: Evolution of productivities of both economies

investments $u$ are independent of time (which is indeed the case for homogeneous technologies), it follows that $\forall t, K^{\mathrm{N}}>K^{\mathrm{S}} \rightarrow G^{\mathrm{N}}>G^{\mathrm{S}}$. The initial productivity for every new technology is zero, thus in (23) it is always the case that $A^{\mathrm{N}}(t)>A^{\mathrm{S}}(t)$.

\subsection{Horizontal innovations}

The solution of a pair of HJB equations derived from (19) under the assumption of constant profits for every next technology yields horizontal innovations investments proportional to expected profit for both countries:

$$
\begin{aligned}
& u^{\mathrm{N}}(t)=\delta_{\mathrm{N}} \pi_{\mathrm{N}}^{R}(N, t) ; \\
& u^{\mathrm{S}}(t)=\delta_{\mathrm{S}} \pi_{\mathrm{S}}^{R}(N, t) .
\end{aligned}
$$

Now, we show that the South, while benefiting from the technological spillover in the development of productivities, invests more than the North in the creation of new technologies. This creates an endogenous specialization effect similar to the one obtained for the dynamic regional monopolies setup in Bondarev (2014).

The expected profit from each technology is defined by two components: accumu- 
lated investments and price of the patent. The specialization of innovative activities comes from the fact that investments for the follower are smaller than for the leader, while the price of the patent is the same in both countries.

We state the first part of this result as a Lemma:

\section{Lemma 2 (Patent prices)}

Patent prices for all technologies are the same across countries,

$$
p_{A}^{\mathrm{N}}(i)=p_{A}^{\mathrm{S}}(i)
$$

Proof: To see this recall that the patent price is defined as the profit stream of the manufacturing sector and thus amounts to the time integral over the relative productivity of the technology $i$ within the operational time, (10).

Subtracting the patent price of the South from that of the North we have an expression constant in time but growing in $i$ :

$$
\begin{gathered}
p_{A}^{\mathrm{N}}(i)-p_{A}^{\mathrm{S}}(i)=\int_{\tau_{\max }}^{\tau_{\min }} \mathrm{e}^{-r\left(t-\tau_{0}\right)} \Pi_{i}^{\mathrm{N}} d t-\int_{\tau_{\max }}^{\tau_{\min }} \mathrm{e}^{-r\left(t-\tau_{0}\right)} \Pi_{i}^{\mathrm{S}} d t= \\
\int_{\tau_{\max }}^{\tau_{\min }} \mathrm{e}^{-r\left(t-\tau_{0}(i)\right)}\left(\begin{array}{l}
\left.\frac{1}{\epsilon} E^{\mathrm{N}} \frac{\left(A_{i}^{\mathrm{N}}\right)^{-\alpha(1-\epsilon)}}{\int_{N_{\max }}^{N_{\min }}\left(A_{j}^{\mathrm{N}}\right)^{-\alpha(1-\epsilon)} d j}\right) \\
-\int_{\tau_{\max }}^{\tau_{\min }} \mathrm{e}^{-r\left(t-\tau_{0}(i)\right)}\left(\frac{1}{\epsilon} E^{\mathrm{S}} \frac{\left(A_{i}^{\mathrm{S}}\right)^{-\alpha(1-\epsilon)}}{\int_{\max }\left(A_{j}^{\mathrm{S}}\right)^{-\alpha(1-\epsilon)}} d j\right.
\end{array}\right) d t
\end{gathered}
$$

At the same time the difference between productivities for both countries is the same for all the technologies:

$$
A_{i}^{\mathbb{N}}(t)-A_{i}^{\mathrm{S}}(t)=\frac{\left(\mathrm{e}^{r t}-\mathrm{e}^{-(\theta+\beta) t}\right)\left(\left(u^{\mathbb{N}}-u^{\mathrm{S}}\right)\left(K_{0}^{\mathbb{N}}-K_{0}^{\mathrm{S}}\right)\right)}{(\theta+\beta+r)\left(N-N_{\text {min }}\right)}
$$

The relative productivity of each technology is then the same in both countries (but total productivity is different) and thus the price for the patent is the same, provided 
expenditures are the same. This is indeed the case since expenditures are constant and proportional to the labor force which is assumed to be equal across countries:

$$
E=\int_{N_{\min }}^{N_{\max }} p^{\mathrm{k}}(i, t) C^{\mathrm{k}}(i, t) d i=\int_{N_{\min }}^{N_{\max }} p^{\mathrm{k}}(i, t) Y^{\mathrm{k}}(i, t) d i=\frac{\epsilon}{\epsilon-1} \int_{N_{\min }}^{N_{\max }} L(i, t) d i=\frac{\epsilon}{\epsilon-1} L .
$$

Then, it follows

$$
p_{A}^{\mathrm{N}}(i)-p_{A}^{\mathrm{S}}(i)=0 .
$$

At the same time the accumulated investments for every technology $i$ are higher for the developed country, since the capital accumulation is faster.

\section{Lemma 3 (Accumulated investments)}

For every technology $i$ accumulated along the total life-cycle, investments into productivity are lower for the follower. In case $K_{0}^{\mathrm{S}}<K_{0}^{\mathrm{N}}$ this turns out to be the South:

$$
\frac{1}{2} \int_{\tau_{0}(i)}^{\tau_{\min }(i)} \mathrm{e}^{-r\left(t-\tau_{0}(i)\right)}\left(g^{\mathrm{S}}(i, t)\right)^{2} d i<\frac{1}{2} \int_{\tau_{0}(i)}^{\tau_{\min }(i)} \mathrm{e}^{-r\left(t-\tau_{0}(i)\right)}\left(g^{\mathrm{N}}(i, t)\right)^{2} d i
$$

Proof: As long as horizontal investments are constant and initial capital endowment is as in the condition of the Lemma it follows,

$$
G^{\mathrm{N}}(t)=K^{\mathrm{N}}(t)-u^{\mathrm{N}}>G^{\mathrm{S}}(t)=K^{\mathrm{S}}(t)-u^{\mathrm{S}} .
$$

Since the investments into each technology are given by (22) and $N-N_{\min }$ is constant we have,

$$
\forall t, \in\left[\tau_{0}(i) ; \tau_{\min }(i)\right], \forall i \in[0 ; N]: g^{\mathrm{S}}(i, t)<g^{\mathrm{N}}(i, t)
$$

Since investments are always nonnegative, the integration and power operations are monotonic w.r.t. the order of relations and the result follows.

Thus, the profit for every new technology (including the boundary one) is higher 
for the less developed country:

$$
\pi_{\mathrm{N}}^{R}(N)-\pi_{\mathrm{S}}^{R}(N)<0
$$

and investments of the follower into variety expansion are higher than that of the leader.

\section{Proposition 4 (Endogenous specialization of innovations)}

With equal labor force and fixed operating costs across countries, the less developed country invests more into new products creation since the expected benefit from a new technology for this country is higher:

$$
\pi_{\mathrm{N}}^{R}(N, t)<\pi_{\mathrm{S}}^{R}(N, t) \rightarrow u^{N}<u^{S}
$$

Proof: The profit from each new technology is given by (20) with $i=N$. The price of the patent is the same by Lemma 2. The accumulated investments are in the relation given by Lemma 3. The result thus follows.

\section{Effects of international spillovers and environ- mental degradation}

\subsection{Comparison with the benchmark model}

Now, we study the effects of international technological spillovers as concerns the growth rates in both economies, where we first neglect environmental degradation.

First, it should be noted that the productivity of individual technologies in the North is the same as without spillovers in the benchmark model. At the same time, the speed of variety expansion is higher since the process of discoveries now benefits from the investments of the other country. Assume the initial range of available technologies is the same for both countries,

$$
N_{0}^{\mathrm{N}}=N_{0}^{\mathrm{S}}=N_{0}
$$

Recall that under autarky the variety expansion for both countries is a linear process, 
yielding a constant range of existing sectors,

$$
\forall \mathrm{k} \in\{\mathrm{N}, \mathrm{S}\}: \dot{N}^{\mathrm{k}}=\dot{N}_{\min }^{\mathrm{k}}=\dot{N}_{\max }^{\mathrm{k}}
$$

However, it follows that the higher is the speed of structural change, the higher is the existing diversity of technologies. Thus, for the leading country the effect of technological spillovers would be a faster turnover of sectors, that is the life-cycle of each technology would be shorter. This boosts structural change in the economy and increases the overall productivity. To see this, compare the range of existing sectors under technological spillovers and without them for both countries:

$$
\begin{aligned}
& \forall \mathrm{k} \in\{\mathrm{N}, \mathrm{S}\}: \\
& N^{\mathrm{k}}(t)=\delta^{2} \pi_{\mathrm{k}}^{R} t+N_{0}, \\
& N_{\text {min }}^{\mathrm{k}}(t)=\delta^{2} \pi_{\mathrm{k}}^{R} t+N_{0}-\tau_{\text {min }}\left(N_{0}\right), \\
& N_{\text {max }}^{\mathrm{k}}(t)=\delta^{2} \pi_{\mathrm{k}}^{R} t+N_{0}-\tau_{\max }\left(N_{0}\right),
\end{aligned}
$$

where $\tau_{\max }\left(N_{0}\right), \tau_{\min }\left(N_{0}\right)$ are the times when the technology $i=N_{0}$ becomes operational and out-dated respectively. The range of existing sectors of the economy is thus defined by,

$$
\forall \mathrm{k} \in\{\mathrm{N}, \mathrm{S}\}: N_{\max }^{\mathrm{k}}(t)-N_{\min }^{\mathrm{k}}(t)=\mathcal{O}^{\mathrm{k}}=\delta^{2} \pi_{\mathrm{k}}^{R}\left(\tau_{\min }\left(N_{0}\right)-\tau_{\max }\left(N_{0}\right)\right)
$$

At the same time, with technological spillovers the variety expansion is faster and, therefore, the range of the operational sectors (core) is wider as long as the profit from each individual technology under autarky is not lower than under spillovers. This is indeed the case since we neglect product market competition and profits from patents in the North are unchanged while in the South they are greater (hence greater productivity than under autarky):

$$
\begin{aligned}
& N^{\mathrm{T}}=\left(\delta_{\mathrm{N}}^{2} \pi_{\mathrm{N}}^{R}+\delta_{\mathrm{s}}^{2} \pi_{\mathrm{S}}^{R}\right) t+N_{0}, \\
& N_{\text {max }}^{\mathrm{T}}(t)-N_{\text {min }}^{\mathrm{T}}(t)=\mathcal{O}^{\mathrm{T}}=\left(\delta_{\mathrm{N}}^{2} \pi_{\mathrm{N}}^{R}+\delta_{\mathrm{S}}^{2} \pi_{\mathrm{S}}^{R}\right)\left(\tau_{\text {min }}\left(N_{0}\right)-\tau_{\text {max }}\left(N_{0}\right)\right),
\end{aligned}
$$


where the superscript $\mathrm{T}$ denotes quantities for the world economy with technological spillovers and the superscript A denotes quantities without spillovers (the autarky case). Then, it is straightforward to see that,

$$
\pi_{\mathrm{N}}^{R} \geq \pi_{\mathrm{A}}^{R}, \pi_{\mathrm{S}}^{R} \geq \pi_{\mathrm{A}}^{R} \rightarrow \mathcal{O}^{\mathrm{T}}>\mathcal{O}_{\mathrm{N}}^{\mathrm{A}} \geq \mathcal{O}_{\mathrm{S}}^{\mathrm{A}}
$$

It is important to note that the effect is strictly positive for the North with any level of the technology gap between countries, since the patent profits in the North are at least the same and in the South they are at least non-zero. The effect of faster structural change and sectoral turnover is observed for both economies, but to a stronger degree for the South, since the patent profits in the South rise to a larger extent. The leading North economy will also benefit from the wider diversity of technologies being operational. The higher speed of structural change thus generates a larger variety of technologies. Figure 2 illustrates the result.

\section{Proposition 5 (Effects of technological spillovers on structural change)}

When technological spillover effects occur, $\theta>0, K_{0}^{\mathrm{N}}>K_{0}^{\mathrm{S}}$, the speed of expansion of variety of technologies, $\dot{N}(t)$, as well as of the out-dating of technologies, $\dot{N}_{\min }(t)$, is faster for both countries:

$$
\forall \mathrm{k} \in\{\mathrm{N}, \mathrm{S}\}: \dot{N}^{\mathrm{T}}=\dot{N}_{m i n}^{\mathrm{T}}=\dot{N}_{m a x}^{\mathrm{T}}>\dot{N}^{\mathrm{k}}=\dot{N}_{\min }^{\mathrm{k}}=\dot{N}_{\max }^{\mathrm{k}}
$$

Therefore, the structural change in the economy with technological spillovers is faster,

$$
\mathcal{O}^{\mathrm{T}}>\mathcal{O}_{\mathrm{N}}^{\mathrm{A}} \geq \mathcal{O}_{\mathrm{S}}^{\mathrm{A}}
$$

Proof: In the absence of spillovers, the profit from each technology in the North is given by,

$$
\pi_{\mathrm{N}}^{R}(i, t)=p_{A}^{\mathrm{N}}(i)-\frac{1}{2} \int_{\tau_{0}(i)}^{\tau_{\min }(i)} \mathrm{e}^{-r\left(t-\tau_{0}(i)\right)}\left(\frac{K^{\mathrm{N}}-u^{\mathrm{N}}}{N^{\mathrm{N}}-N_{m i n}^{\mathrm{N}}}\right)^{2} d i .
$$

With spillovers, the productivity of each technology in the North is the same, and 


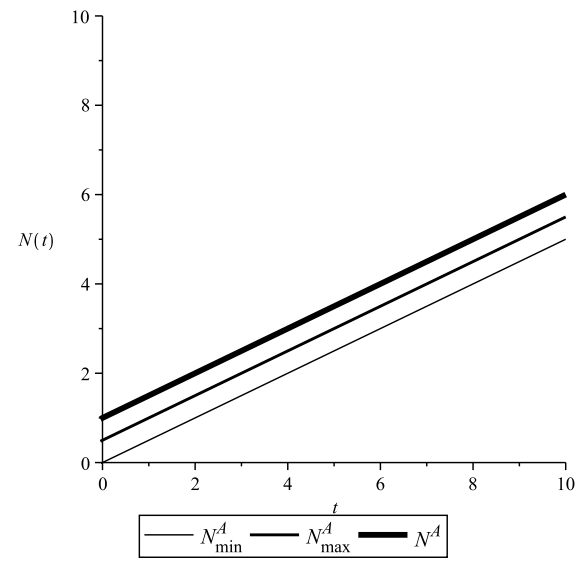

(a) Variety expansion under autarky

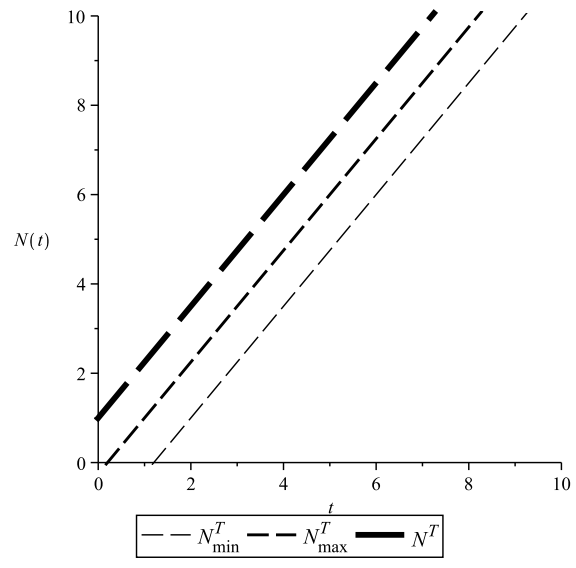

(b) Variety expansion under spillovers

Figure 2: Horizontal innovations and expansion of the core

the difference in profits may come only from the changes in integration limits in patent price and accumulated investments. However, these limits change in the same direction and by the same amount given a linear variety expansion process. Thus, the profits from vertical innovations in the North would remain unchanged under spillovers.

In the South productivity of technologies is higher under the spillover and thus profits are higher than without the spillover. Thus we have (41).

Because of this, the variety expansion is boosted in comparison to the autarky case and we have (42). Since processes of $N_{\max }$ and $N_{\min }$ are just shifts of a linear $N$ process, we have (43).

Now, consider that the rate of output growth for such an economy is,

$$
\frac{\dot{Y}^{\mathrm{N}, \mathrm{S}}}{Y^{\mathrm{N}, \mathrm{S}}}=\alpha \frac{\dot{\bar{A}}^{\mathrm{N}, \mathrm{S}}}{\bar{A}^{\mathrm{N}, \mathrm{S}}}\left(N_{\max }-N_{\min }\right)>0,
$$

where $\bar{A}$ denotes the average productivity. For the North this means that the average productivity growth rate is unchanged but the core of the economy is larger and, thus, economic growth is higher:

$$
\frac{\dot{Y}_{\mathrm{A}}^{\mathrm{N}}}{Y_{\mathrm{A}}^{\mathrm{N}}}=\alpha \frac{\dot{\bar{A}}}{\bar{A}} \mathcal{O}^{\mathrm{A}}<\frac{\dot{Y}_{\mathrm{T}}^{\mathrm{N}}}{Y_{\mathrm{T}}^{\mathrm{N}}}=\alpha \frac{\dot{\bar{A}}}{\bar{A}} \mathcal{O}^{\mathrm{T}}
$$


where superscript $\mathrm{N}$ indicates North and subscripts A, T denote quantities in autarky and under technological spillovers.

Now, turn to the South. For the less developed country the technological spillover is even more beneficial, since both the range of technologies being used is increased compared to the autarky regime and the average productivity of each technology is higher because of technological spillovers from the leader:

$$
\begin{aligned}
& \frac{\dot{\bar{A}}_{\mathrm{A}}^{\mathrm{S}}}{\bar{A}_{\mathrm{A}}^{\mathrm{S}}}<\frac{\dot{\bar{A}}_{\mathrm{T}}^{\mathrm{S}}}{\bar{A}_{\mathrm{T}}^{\mathrm{S}}} ; \\
& \mathcal{O}^{\mathrm{A}}<\mathcal{O}^{\mathrm{T}} ; \\
& \frac{\dot{Y}_{\mathrm{A}}^{\mathrm{S}}}{Y_{\mathrm{A}}^{\mathrm{S}}}<<\frac{\dot{Y}_{\mathrm{T}}^{\mathrm{S}}}{Y_{\mathrm{T}}^{\mathrm{S}}}
\end{aligned}
$$

Thus, the technology sharing would be beneficial for both economies without any drawbacks. The rate of growth of the world economy is the sum of the growth rates of North and South and is higher with technological spillovers than without them.

\section{Proposition 6 (World economy with technological spillovers)}

When the technological spillover from the North to the South takes place, the following effects are observed:

1. The range of operating sectors in both economies is higher than without the spillover, $\mathcal{O}^{\mathrm{T}}>\mathcal{O}^{\mathrm{A}}$;

2. The productivity of each technology is the same in the North as if no spillover occured, $A_{\mathrm{T}}^{\mathrm{N}}(i, t)=A_{\mathrm{A}}^{\mathrm{N}}(i, t)$;

3. Productivity for each technology in the South is higher due to the technology spillover, $A_{\mathrm{T}}^{\mathrm{S}}(i, t)>A_{\mathrm{A}}^{\mathrm{S}}(i, t)$;

4. Output growth in both economies is higher as well as the growth rate of the world economy, $\frac{\dot{Y}_{\mathrm{T}}^{\mathrm{N}}}{Y_{\mathrm{T}}^{\mathrm{N}}}>\frac{\dot{Y}_{\mathrm{A}}^{\mathrm{N}}}{Y_{\mathrm{A}}^{\mathrm{N}}}, \frac{\dot{Y}_{\mathrm{T}}^{\mathrm{S}}}{Y_{\mathrm{T}}^{\mathrm{S}}}>\frac{\dot{Y}_{\mathrm{A}}^{\mathrm{S}}}{Y_{\mathrm{A}}^{\mathrm{S}}}, \frac{\dot{Y}_{\mathrm{T}}^{\mathrm{W}}}{Y_{\mathrm{T}}^{\mathrm{W}}}>\frac{\dot{Y}_{\mathrm{A}}^{\mathrm{W}}}{Y_{\mathrm{A}}^{\mathrm{W}}}$

Proof: 1. amounts to Proposition 5; 2. and 3. follow from (23); 4. is obtained by direct computations performed above. 


\subsection{The extended model with environmental degradation}

Now, we extend the basic model analyzed above to take into account the interrelation between the economy and the environment. To do so we assume that the change of the environment is described by the following differential equation:

$$
\dot{T}=-\mu T+e Y^{\mathrm{W}}
$$

where:

- $T$ is some aggregate measure of the environment (temperature increase above pre-industrial level);

- $\mu$ is the regeneration rate in the absence of industrial activity;

- $e$ is the intensity of emissions, defined by the state of technology;

- $Y^{\mathrm{w}}$ is the aggregate output of the world economy.

The intensity of emissions is defined as a mix of technologies currently in use in both countries, weighted by the share of output produced with these technologies:

$$
e=e_{0} \frac{\int_{N_{\min }}^{N_{\max }}(1 / i) y_{i} d i}{\mathcal{O}},
$$

with $y_{i}$ denoting the share of world output for technology $i$. Note that, due to the assumption of a common range of technologies for both countries, the emissions intensity is defined over the common range and no separate functions are necessary. The parameter $e_{0}$ is the estimate of the initial intensity of emissions. In the numerical example presented below, we assume that 0.0475 of the total output is transferred into the temperature increase along the lines of Nordhaus (2007).

The influence of the environment on economic activity is modelled through a damage function. Environmental degradation reduces production capabilities in the economies but, since it is an externality, it is not taken into account by the manufacturing sector. 
The aggregate output now is given by,

$$
Y^{\mathrm{W}}(t)=\frac{1}{1+T}\left(\int_{\mathrm{N}_{\min }}^{N_{\max }} Y^{\mathrm{N}}(i, t) d i+\int_{N_{\min }}^{N_{\max }} Y^{\mathrm{S}}(i, t) d i\right),
$$

with $1 /(1+T)$ reflecting environmental damages. Since all of the output of the manufacturing sector is consumed, such a specification is equivalent to the reduction in consumption of every product within the operational range and to a proportional increase in prices:

$$
\begin{aligned}
& \forall \mathrm{k} \in\{\mathrm{N}, \mathrm{S}\}: \\
& C_{i}^{\mathrm{k}, T}=\frac{1}{1+T} Y_{i}^{\mathrm{k}, O} ; \\
& P_{i}^{\mathrm{k}, T}=(1+T) P_{i}^{\mathrm{k}, O} ; \\
& L_{i}^{\mathrm{k}, T}=\frac{1}{1+T} L_{i}^{\mathrm{k}, O},
\end{aligned}
$$

with superscripts $T, O$ denoting the world economy with and without environmental impact, respectively.

Thus, total expenditures in both economies are still constant and are unaffected by the state of environment:

$$
\forall \mathrm{k} \in\{\mathrm{N}, \mathrm{S}\}: E^{\mathrm{k}, T}=\int_{N_{\min }}^{N_{\max }} P_{i} C_{i} d i=E^{\mathrm{k}, O},
$$

since the impact on the prices and on labour employed by different sectors cancels out. Following the same lines as for the stand-alone model without technological spillovers in Bondarev and Greiner (2014b), it can be demonstrated that environmental degradation leads to a decrease in labour income and in capital accumulation, making it harder to raise the productivity of the economy:

$$
\forall \mathrm{k} \in\{\mathrm{N}, \mathrm{S}\}: \dot{K}^{\mathrm{k}, T}=r K^{\mathrm{k}, T}-E^{O}+\frac{1}{1+T}<\dot{K}^{\mathrm{k}, O} .
$$


The capital accumulation is decreased in the same way for both the North and the South, decreasing productivity growth symmetrically in both countries:

$$
\begin{aligned}
& \dot{A}^{\mathrm{N}, T}(i, t)=\frac{K^{\mathrm{N}, T}-u^{\mathrm{N}}}{N-N_{m i n}}-\beta A^{\mathrm{N}, T}(i, t)<\dot{A}^{\mathrm{N}, O} \\
& \dot{A}^{\mathrm{S}, T}(i, t)=\frac{K^{\mathrm{S}, T}-u^{\mathrm{S}}}{N-N_{\min }}-\beta A^{\mathrm{S}, T}(i, t)+\theta\left(A^{\mathrm{N}, T}(i, t)-A^{\mathrm{S}, T}(i, t)\right)<\dot{A}^{\mathrm{S}, O} .
\end{aligned}
$$

Nevertheless, the patent prices are higher than in the model without environmental damages, since the profits of the manufacturing sector are unaffected. The decrease in output is balanced by the increase in prices and labor costs are lower:

$$
\begin{aligned}
& \forall \mathrm{k} \in\{\mathrm{N}, \mathrm{S}\}: \\
& \Pi_{i}^{\mathrm{k}, T}=P_{i}^{\mathrm{k}, T} Y_{i}^{\mathrm{k}, T}-L_{i}^{\mathrm{k}, T}-\Psi=\left(\frac{\epsilon}{\epsilon-1}-\frac{1}{1+T}\right) L_{i}^{\mathrm{k}, O}-\Psi ; \\
& \Pi_{i}^{\mathrm{k}, O}=P_{i}^{\mathrm{k}, O} Y_{i}^{\mathrm{k}, O}-L_{i}^{\mathrm{k}, O}-\Psi=\left(\frac{\epsilon}{\epsilon-1}-1\right) L_{i}^{\mathrm{k}, O}-\Psi ; \\
& T \geq 0: \Pi_{i}^{\mathrm{k}, T} \geq \Pi_{i}^{\mathrm{k}, O} .
\end{aligned}
$$

Due to the magistrale property of the productivity dynamics (during the operational phase all of the technologies follow the same evolution path) and due to the definition of the time integration limits of the patent price, it follows that patent prices are unchanged by the slowdown of capital accumulation. This results from the fact that productivities of all technologies within the operational phase are lowered by exactly the same amount. But, this does not mean that the productivity of new technologies is the same.

At the same time, the accumulated investments into productivity growth are lower for both countries because of lower capital stocks. As a result, the expected profit for each new technology is increasing despite the decrease in productivity itself. Indeed, the decrease of productivity does not lead to a decrease in the patent price so that the development of new technologies becomes more attractive: one may get the same price with lower investments. 
Since the profit from patents for both countries is higher under environmental degradation, the process of variety expansion is accelerated and the operational range of technologies rises:

$$
\pi_{\mathrm{N}, \mathrm{S}}^{T}>\pi_{\mathrm{N}, \mathrm{S}}^{O} \rightarrow \dot{N}_{\mathrm{N}, \mathrm{S}}^{T}>\dot{N}_{\mathrm{N}, \mathrm{S}}^{T} \rightarrow \mathcal{O}_{\mathrm{N}, \mathrm{S}}^{T}>\mathcal{O}_{\mathrm{N}, \mathrm{S}}^{O}
$$

We summarize these results in the following Proposition:

\section{Proposition 7 (Influence of environmental degradation)}

In the world economy with technological spillovers, the presence of environmental degradation described by (48) and (50) leads to the following effects:

1. Decrease in labour demand compared to the basic model, $L_{i}^{\mathrm{k}, T}=\frac{1}{1+T} L_{i}^{\mathrm{k}, O}$;

2. Decrease in productivity of all the technologies, given by (54), (55);

3. Increase in the speed of variety expansion and of structural change, (59).

Proof: 1. Follows from (50) and (51); 2. follows from depressed capital accumulation, (53); 3. follows from increased final producers profits, (58).

Recall that the growth rate of the economy is given by (45). It is straightforward to see that the growth rate of the average productivity is lower under environmental pollution while the range of operational sectors is wider. Hence, the exact difference between the economic growth rates of the world economy with and without environmental degradation cannot be determined in general.

It should be noted that the range of operational sectors does not change over time and depends only on the initial range of technologies, as in (40). At the same time,

if the world temperature rises, $\dot{T}>0$, the growth rate of the average productivity declines and it is not constant as in the model without the environment, since the capital growth rate decreases:

$$
\frac{\dot{\bar{A}}}{\bar{A}} \sim \frac{\dot{K}}{K}
$$


This creates additional stimuli for international technological spillovers as defined above. That holds because boosting structural change would not only increase overall economic growth but also speed up the introduction of cleaner technologies in both economies, thus, decreasing the emissions intensity and slowing down output degradation.

\subsection{Effects of environmental degradation with and without technological spillovers}

In this subsection, we compare the evolution of the environment in the economy without technological spillovers to the case of an economy featuring such spillovers. We already established the stimulating effect of technological spillovers on the economic and R\&D development of both countries and discussed the changes being brought about by the presence of environmental damages in that model. It is then straightforward to expect that the environmental impact of the world economy should be lower with technological spillovers than without them. This result would be of limited interest since it has already been discussed in the environmental economics literature, but our model enables us to highlight the role of endogenous structural change in this process.

Consider the total environmental impact of the world economy:

$$
\dot{T}=-\mu T+e_{0} \frac{\int_{N_{\min }}^{N_{\max }}(1 / i) y_{i}^{\mathrm{W}} d i}{\mathcal{O}} Y^{\mathrm{W}}
$$

In what follows we denote with the superscript $\mathrm{T}$ quantities for the world economy with technological spillovers and environmental pollution and by the superscript A quantities for the autarky regime with environmental degradation (but no technological spillovers).

The world output is equivalent to the sum of sectoral outputs in both economies. 
With technological spillovers, both countries share the same technological space:

$$
Y^{\mathrm{W}, \mathrm{T}}=\int_{N_{\min }}^{N_{\max }}\left(Y_{i}^{\mathrm{N}}+Y_{i}^{\mathrm{S}}\right) d i
$$

while under autarky the range of technologies can be different:

$$
Y^{\mathrm{W}, \mathrm{A}}=\int_{N_{\min }^{\mathrm{N}}}^{N_{\max }^{\mathrm{N}}} Y_{i}^{\mathrm{N}} d i+\int_{N_{\min }^{\mathrm{s}}}^{N_{\max }^{\mathrm{S}}} Y_{i}^{\mathrm{S}} d i
$$

yielding a different denominator $\mathcal{O}$ in the evolution of the environment (61).

Sectoral outputs (with environmental impact) are functions of relative productivities in both scenarios:

$$
Y_{i}^{\mathrm{k}}=\frac{1}{1+T}\left(\frac{\left(A^{\mathrm{k}}(i, t)\right)^{\alpha \epsilon}}{\int_{N_{m i n}^{\mathrm{k}}}^{N_{m a x}^{\mathrm{k}}}\left(A^{\mathrm{k}}(j, t)\right)^{\alpha(\epsilon-1)} d j}\right),
$$

so that the world output can be expressed as,

$$
Y^{\mathrm{W}}=\frac{1}{1+T}\left(\frac{\int_{\max }^{N_{\operatorname{Nin}}^{\mathrm{N}}}\left(A^{\mathrm{N}}(i, t)\right)^{\alpha \epsilon} d i}{\int_{N_{\min }^{\mathrm{N}}}^{N_{\max }^{\mathrm{N}}}\left(A^{\mathrm{N}}(j, t)\right)^{\alpha(\epsilon-1)} d j}+\frac{\int_{N_{\min }^{\mathrm{S}}}^{N_{\operatorname{sax}}^{\mathrm{S}}}\left(A^{\mathrm{S}}(i, t)\right)^{\alpha \epsilon} d i}{\int_{N_{\min }^{\mathrm{S}}}^{N_{\max }^{\mathrm{S}}}\left(A^{\mathrm{S}}(j, t)\right)^{\alpha(\epsilon-1)} d j}\right) .
$$

The world share of technology $i$ is

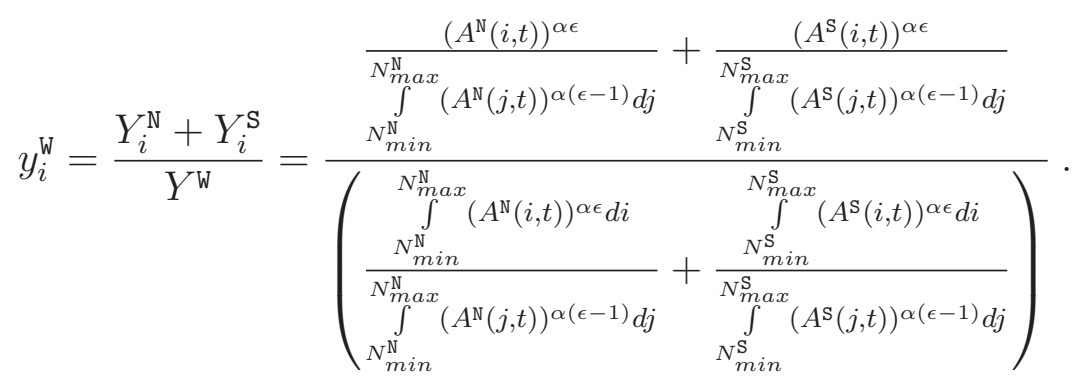

Depending on whether the variety of technologies coincides for both countries (under 
the spillover scenario) or not, one obtains two different expressions for the evolution of the environment. For the economy with technological spillover one gets:

$$
\dot{T}^{\mathrm{T}}=\frac{e_{0}}{1+T^{\mathrm{T}}} \frac{1}{\mathcal{O}^{\mathrm{T}}}\left(\frac{\int_{N_{m i n}^{\mathrm{T}}}^{N_{m a x}^{\mathrm{T}}}(1 / i)\left(A^{\mathrm{N}, \mathrm{T}}(j, t)\right)^{\alpha \epsilon} d i}{\int_{N_{\min }^{\mathrm{T}}}^{N_{m a x}^{\mathrm{T}}}\left(A^{\mathrm{N}, \mathrm{T}}(j, t)\right)^{\alpha(\epsilon-1)} d j}+\frac{\int_{N_{\text {man }}^{\mathrm{T}}}^{N_{\operatorname{T}}^{\mathrm{T}}}(1 / i)\left(A^{\mathrm{S}, \mathrm{T}}(j, t)\right)^{\alpha \epsilon} d i}{\int_{N_{m i n}^{\mathrm{T}}}^{N_{m a x}^{\mathrm{T}}}\left(A^{\mathrm{S}, \mathrm{T}}(j, t)\right)^{\alpha(\epsilon-1)} d j}\right)-\mu T^{\mathrm{T}},
$$

and for the economy without technological spillover (autarky):

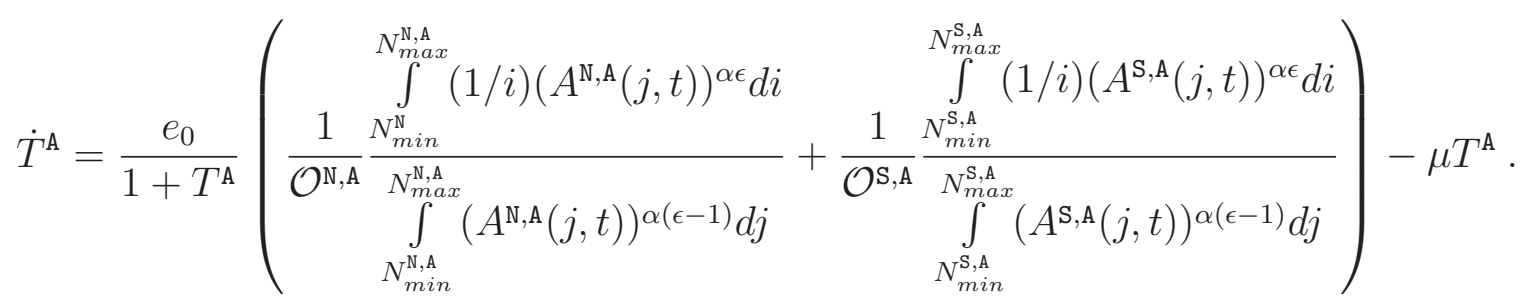

The terms in brackets are the environmental impacts of the individual economies of the North and the South. As long as the world economy is in steady state, all productivities grow at the same average speed (country-specific), $\dot{A}_{i}^{\mathrm{k}}=\dot{\bar{A}}^{\mathrm{k}}$, and one can get rid of integration terms, yielding for the economy under spillovers,

$$
\dot{T}^{\mathrm{T}}=\frac{e_{0}}{1+T^{\mathrm{T}}}\left(\frac{1}{\left(\mathcal{O}^{\mathrm{T}}\right)^{2}} \ln \left(N_{\max }^{\mathrm{T}} / N_{\min }^{\mathrm{T}}\right)\left(\left(\bar{A}^{\mathrm{N}, \mathrm{T}}\right)^{\alpha}+\left(\bar{A}^{\mathrm{S}, \mathrm{T}}\right)^{\alpha}\right)\right)-\mu T^{\mathrm{T}}
$$

and for the economy without it,

$$
\dot{T}^{\mathrm{A}}=\frac{e_{0}}{1+T^{\mathrm{A}}}\left(\frac{1}{\left(\mathcal{O}^{\mathrm{N}, \mathrm{A}}\right)^{2}} \ln \left(N_{\max }^{\mathrm{N}, \mathrm{A}} / N_{\min }^{\mathrm{N}, \mathrm{A}}\right)\left(\bar{A}^{\mathrm{N}, \mathrm{A}}\right)^{\alpha}+\frac{1}{\left(\mathcal{O}^{\mathrm{S}, \mathrm{A}}\right)^{2}} \ln \left(N_{\max }^{\mathrm{S}, \mathrm{A}} / N_{\min }^{\mathrm{S}, \mathrm{A}}\right)\left(\bar{A}^{\mathrm{S}, \mathrm{A}}\right)^{\alpha}\right)-\mu T^{\mathrm{A}}
$$

From the previous analysis it follows that the intensity of emissions is lower under spillovers leading to,

$$
\frac{1}{\left(\mathcal{O}^{\mathrm{T}}\right)^{2}} \ln \left(N_{\text {max }}^{\mathrm{T}} / N_{\text {min }}^{\mathrm{T}}\right)<\frac{1}{\left(\mathcal{O}^{\mathrm{N}, \mathrm{A}}\right)^{2}} \ln \left(N_{\text {max }}^{\mathrm{N}, \mathrm{A}} / N_{\text {min }}^{\mathrm{N}, \mathrm{A}}\right)+\frac{1}{\left(\mathcal{O}^{\mathrm{S}, \mathrm{A}}\right)^{2}} \ln \left(N_{\max }^{\mathrm{S}, \mathrm{A}} / N_{\text {min }}^{\mathrm{S}, \mathrm{A}}\right)
$$


since the presence of spillovers boosts structural change and the turnover of sectors in the economy, yielding a wider diversity of sectors, $\mathcal{O}$, and a lower intensity $\ln \left(N_{\max } / N_{\min }\right)$.

However, the average productivity of the world economy is higher in the scenario with technological spillover than without it. Thus, the actual dynamics of the environment depends on the relative size of these two effects: reduction in intensity of emissions and increase in productivity. We established in Proposition 1 above that the North productivity is unaffected by the spillover itself, $\bar{A}^{\mathrm{N}, \mathrm{T}}=\bar{A}^{\mathrm{N}, \mathrm{A}}$. Hence, the increase of the overall influence on the environment only comes from the increase of the productivity in the South. At the same time, the intensity of emissions in the South is also affected by the technological spillover, given a lower productivity in this country. Therefore, overall the environmental degradation is expected to be lower in the case with spillovers than under autarky.

We resort to a numerical example with parameters as given in Table 1 to illustrate this discussion.

Table 1: Parameters values used in Figures 3 and 4.

\begin{tabular}{cc}
\hline \hline Parameter & Value \\
\hline$N_{0}^{\mathrm{T}}=N_{0}^{\mathrm{N}, \mathrm{A}}=N_{0}^{\mathrm{S}, \mathrm{A}}$ & 1 \\
$r$ & 0.05 \\
$\beta$ & 0.1 \\
$\mu$ & 0.4 \\
$\theta$ & 0.4 \\
$e_{0}$ & 0.0475 \\
$\pi_{\mathrm{N}, \mathrm{T}}^{R}=\pi_{\mathrm{N}, \mathrm{A}}^{R}$ & 0.25 \\
$\pi_{\mathrm{S}, \mathrm{T}}^{R}$ & 0.75 \\
$\pi_{\mathrm{S}, \mathrm{A}}^{R}$ & 0.5 \\
$\tau_{\min }\left(N_{0}\right)$ & 3 \\
$\tau_{\max }\left(N_{0}\right)$ & 1 \\
$\delta_{\mathrm{N}}=\delta_{\mathrm{S}}$ & 0.5 \\
\hline \hline
\end{tabular}

In Figure 3 it is shown that the productivity grows only in the South, while the overall intensity of emissions of both countries, given in (71), is lower in the spillover case. Since the contributions to the environmental degradation of both the South and 
the North are dynamic and are given as products of productivities and intensities, one can conclude that the effect of cleaner technologies should dominate the effect of the output increase.

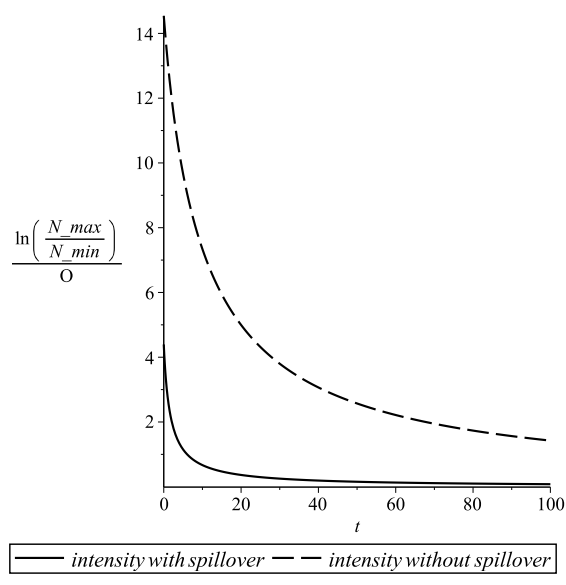

(a) Intensity of emissions

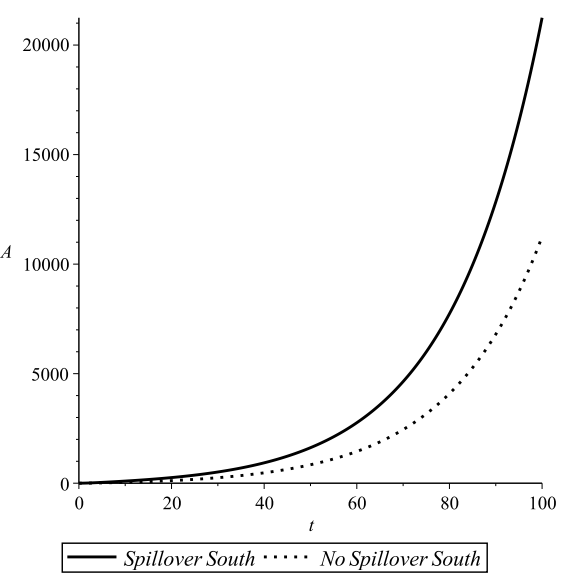

(b) Productivity growth

Figure 3: Relative dynamics of intensities and productivity

Proposition 8 summarizes the results of our discussions.

\section{Proposition 8 (Influence of technological spillover on environment)}

In the world economy with environmental degradation given by (51), the technological spillover is expected to reduce environmental pollution in the world economy and leads to a boost of output both in the North and in the South.

Proof: The boost in output growth follows from the Proposition 6. A comparison of the growth rates of the intensity of emissions, (71), and of the productivity increase yields the result of a slowdown in environmental degradation.

Figure 4 illustrates the environmental dynamics with the parameter values from Table 1. It can be seen that the change of the environment (measured as the increase in the average surface temperature) is much less drastic in the presence of technological spillovers: the temperature decreases to pre-industrial levels in 100 years before it begins to rise, while without spillovers we get the typical result of an increasing temperature over 3.5 degrees Celsium, which is in line with other more detailed and empirical estimations. 


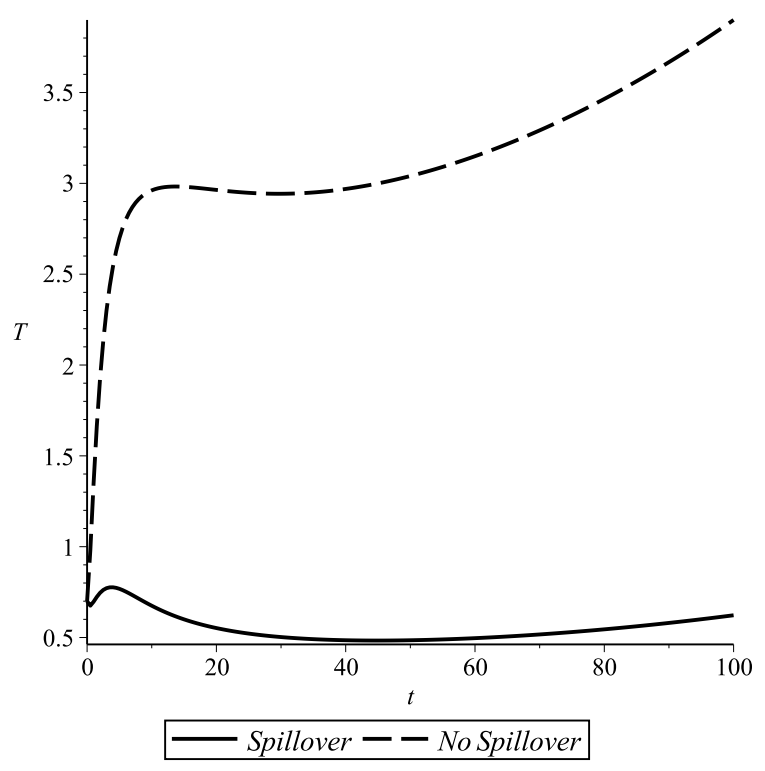

Figure 4: Evolution of environment with and without technological spillover

It should also be pointed out that environmental degradation continues in the longrun as output grows unless resource are used for abatement. The simplest way to achieve a constant level of the environment would be to levy a lump-sum tax and to use the tax revenue for abatement, for example. The question of how environmental pollution can be stabilized in growing economies has been the subject of a great many studies (see e.g. the models in Greiner and Semmler (2008)). Therefore, we do not treat this problem but, rather, focus on the relation between structural change, economic growth and environmental pollution in a North-South context, with the environment determined by the decisions of private agents alone.

\section{Discussion}

Technological spillovers between countries lead to an acceleration of structural change and to an increase of output growth rates. At the same time, if one assumes newer technologies to be cleaner and less harmful for the environment than older ones, this technological spillover also slows down environmental degradation, thus, reducing the temperature increase. Hence, the goal of fostering structural change through technolog- 
ical spillovers is worth pursuing both from economic and environmental perspectives.

It is clear that the results obtained in the paper are model-specific and their robustness depends on some assumptions in the model. First, the absence of competition on product markets should be discussed. From the analysis above it follows that prices for final products are lower in the North and output in each sector is higher. This happens because of the gap in productivities for all the technologies between countries. This would create an incentive for the North to export its products to the South, but domestic demand is sufficient to consume all of the output with lower prices. Opening up trade in goods and not only in technologies would equalize prices between countries (assuming negligible trading costs) and boost output in the North even further. The South, while experiencing lower prices than under autarky, would decrease production but still benefit from higher productivity growth so that output would be higher than under autarky. Therefore, the consideration of product market competition is possible within the suggested framework but will not lead to qualitatively new insights.

Second, we limited the analysis to homogeneous vertical innovations, while the partial equilibrium model in Bondarev (2014) deals with heterogeneity in investment efficiencies. The homogeneity of vertical innovations is crucial to obtain a linear growth of variety of technologies. If one allows for heterogeneous innovations, the horizontal innovation process becomes non-linear since profits of vertical R\&D would no longer be constant. In this case the solution for the R\&D problem would depend on regularity conditions of the heterogeneity characteristics of innovations. It is difficult at the moment to formally establish the same results for such an extension as for the homogeneous version. However, our conjecture is that the majority of results, especially on the beneficial nature of technological spillovers, would hold in this context, too.

On the other hand, the model presented in this paper is robust to the increase in the number of participating countries and all results can be easily extended to any finite number of countries. The benefits from spillovers, then, will depend on the relative positions of the countries with the most advanced economy reaping the smallest economic benefits. Environmental benefits, however, would increase symmetrically for all participants. This raises an interesting free-rider problem: the most advanced 
country may try to prevent spillovers and still benefit from the better state of the environment. But, it is important to note that the differential game concept used for the R\&D solution in this paper does not use any concept of cooperative solution and spillovers are beneficial for all parties.

In solving the R\&D game, this paper resorted to the open-loop concept. The implementation of the closed-loop equilibrium concept to the model should only increase the degree of specialization of countries in the same way as in the partial equilibrium model by Bondarev (2014) used as a benchmark for the R\&D sector in this framework. The difference in technology decay rates, $\beta$, may lead to the convergence of the technological state of the follower to the one of the leader, but this would require a more detailed study.

To conclude, the presented framework, while allowing multiple directions of extensions, is robust enough to preserve the beneficial effects of technological spillovers on the speed of structural change, defined as the speed of sectoral turnover in the economy, and on the state of the environment. We have seen that technology spillovers from the North to the South raise structural change in both economies as well as economic growth. The latter is higher compared to a world under autarky. Further, we could also show that environmental degradation in the world economy is expected to be lower compared to the autarky case since a faster structural change implies that newer and cleaner technologies sooner replace older and dirtier ones. 


\section{References}

Alemdar, N.M. and Özyildrim, S. (1998). A genetic game of trade, growth and externalities. Journal of Economic Dynamics and Control, 22(6):811-32.

Alemdar, N.M. and Özyildrim, S. (2002). Knowledge spillovers, transboundary pollution, and growth. Oxford Economic Papers, 54(4):597-616.

Baldwin, R.E. and Robert-Nicoud, F. (2008). Trade and growth with heterogeneous firms. Journal of International Economics, 74(1):21-34.

Bondarev, A. (2014). Endogenous specialization of heterogeneous innovative activities of firms under the technological spillovers. Journal of Economic Dynamics and Control, 38(0):235-49.

Bondarev, A. and Greiner, A. (2014a). Endogenous growth and structural change through vertical and horizontal innovations. Working papers in Economics and Management 03-2014, Bielefeld University.

Bondarev, A. and Greiner, A. (2014b). Environmental pollution in a growing economy with endogenous structural change. Working papers in Economics and Management 07-2014, Bielefeld University.

Chichilinsky, G. (1994). North-South trade and the global environment. The American Economic Review, 84(4):851-74.

Dockner, E., Jorgensen, S., Long, N., and Sorger, G. (2000). Differential Games in Economics and Management Sciences. Cambridge University Press, Cambridge.

Greiner, A. and Semmler, W. (2008). The Global Environment, Natural Resources, and Economic Growth. Oxford University Press, New York.

Grimaud, A. and Rouge, L. (2004). Polluting non-renewable resources, tradeable permits and endogenous growth. International journal of global environmental issues, $4(1): 38-57$. 
Nordhaus, W.D. (1967). The optimal life of a patent. Cowles Foundation discussion paper \#241,.

Nordhaus, W. (2007). The challenge of global warming: economic models and environmental policy, volume 4. Yale University.

Peretto, P.F. and Connolly, M. (2007). The manhattan metaphor. Journal of Economic Growth, 12(4):329-350.

Rivera-Batiz, L.A. and Romer, P.M. (1991). International trade with endogenous technological change. Quarterly journal of economics, 106(2):531-55.

Romer, P.M. (1990). Endogenous technological change. Journal of Political Economy, 98(5):S71-S102.

Unel, B. (2010). Technology diffusion through trade with heterogeneous firms. Review of International Economics, 18(3):465-81. 